\title{
NMR T1-T2 Map of Different Hydrogen Contents of Bakken Formation
}

\author{
Seyedalireza Khatibi, Mehdi Ostadhassan, Azadeh Aghajanpour, and Rehan Ali Mohammed
}

\begin{abstract}
The development of shale reservoirs has interpreted as a milestone in the energy equation. This issue led to organicrich oil-producing mudrocks to be studied extensively during the last decade. Shale reservoirs properties such as pore size, organic matter, wettability, clay content and mineralogy would limit the application of the conventional methods for characterizing such reservoirs.

Nuclear Magnetic Resonance (NMR) relaxation method is a crucial technique for evaluating shales rocks, both core and log scale. Utilizing NMR tool to measure relaxation times (ranging from 0.1-1 ms) provides a way to understand small pore sizes (nano-meter scale) and also to investigate different proton populations using 2D T1-T2 maps.

We took some samples from upper and lower Bakken formation with different maturity levels. Then, the position of each proton population such as hydroxyls from the clay, water, kerogen, and hydrocarbon was detected in samples. Results showed, in a T1-T2 map, the position of these signatures do not overlap and also shows the movability of each portion as well.
\end{abstract}

Index Terms-Nuclear Magnetic Resonance (NMR), shale reservoirs, proton populations, T1-T2 map.

\section{INTRODUCTION}

The fully characterization of gas shales still remained a challenge, since it cannot be performed by means of conventional petrophysical techniques, and new techniques are required for characterizing shale reservoirs. Even for porosity and permeability as basic properties, special methodologies are required. Standard measurement of pore sizes as well as advanced microscopic techniques such as SEM have shown the existence of very small pores [1]-[4].

NMR is a versatile technique used previously to study soluble and insoluble hydrocarbon mixtures, such as kerogen [5]-[9], bitumen [10], [11], petroleum [12], [13], and asphaltenes [13]-[15]. Reference [16] used the T1/T2 ratio to differentiate between moveable and non-moveable fluids in both conventional and unconventional reservoirs. In Smectites having sheet-like pores, NMR instrument can detect and quantify the interlayer water content [3].

It should be noted, simple 1D NMR are not sufficient due to complex porous media [17]. There is also a potential

Manuscript received March 8, 2018; revised May, 20, 2018.

Seyedalireza Khatibi, Mehdi Ostadhassan and Rehan Ali Mohammed are with the University of North Dakota, Grand Forks, ND, USA (e-mail: seyedalireza.khatibi@und.edu, mehdi.ostadhassan@engr.und.edu,).

Azadeh Aghajanpour is with the Curtin University Malaysia, Miri, Sarawak, Malaysia (e-mail: azadehaghajanpour@gmail.com). overlapping of the signals of different Hydrogen (H) populations. Multidimensional NMR techniques improve the separation of the different proton contributions [8]-[18]. In this study, T1-T2 map was used in conjunction with geochemical data to characterize hydrogen content in pore spaces of two samples from upper and lower Bakken. The hydrogen population were distinguished straightforward in $2 \mathrm{D}$ T1-T2 map. Interestingly, presence of hydrocarbon which was detected in NMR in one of the wells in this study, was also seen in UV image.

\section{DATA AND SAMPLES}

For this study, samples were chosen from the upper and lower members of the Bakken Formation and analyzed with Rock-Eval and also NMR. The Bakken Formation is an organic rich shale, mudstone and sandstone that was deposited during the Late Devonian and Early Mississippian Periods [19]. It is located in the Williston Basin, which is an elliptical shaped depression located in the western portion of North Dakota, northeastern region of Montana and extends into parts of Saskatchewan and Manitoba [20]. The lower and upper members contain Type-I and Type-II organic matter that originated from marine algae. The total organic carbon (TOC) has a maximum of $30 \%$ and $20 \%$ in the upper and lower members, respectively [21].

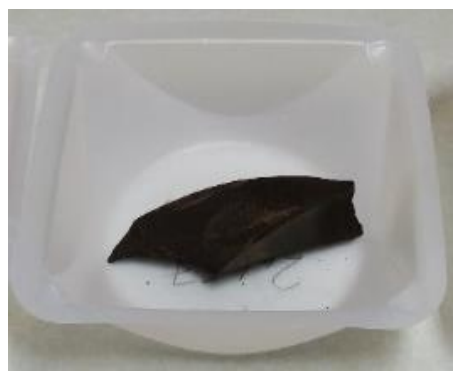

(a)

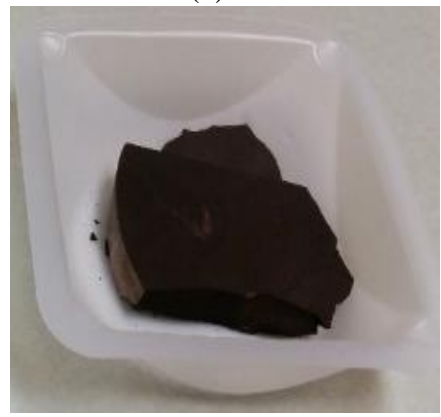

(b)

Fig. 1. Photo of raw samples for Well No. 1 (a) and Well No. 2 (b). 
Fig. 1 shows raw sample chips used for this study, Table I also presents sample properties from Rock-Eval. No special sample preparation but routine was carried out.

\begin{tabular}{|c|c|c|c|c|}
\hline $\begin{array}{l}\text { Well } \\
\text { No. }\end{array}$ & $\begin{array}{l}\text { Sample depth } \\
\text { (ft) }\end{array}$ & TOC (wt \%) & $\operatorname{Ro}(\%)$ & $\mathbf{T}_{\max }\left({ }^{\circ} \mathrm{C}\right)$ \\
\hline 1 & 8326 (U.B) & 16.27 & 0.54 & 428 \\
\hline 2 & 10555 (L.B) & 13.26 & 0.86 & 449 \\
\hline
\end{tabular}

\section{NMR MEASUREMENT}

Organic-rich oil-producing mudrocks has become a major exploration target, thus understanding pore network of such fine grained rocks is crucial for optimizing and designing expenses of production. NMR relaxation methods are considered as key techniques for evaluating oil-producing mudrocks, from both cores and logging data. Fig. 2 shows pore system in a shale rock from [2]. Recently, NMR is being widespread for characterizing of shale oil and shale gas reservoirs by showing producible zones in log scale and pore size distribution in core scale. T1 and T2 are longitudinal and transverse relaxtion times of $\mathrm{H}$ nuclei in rock which can be measured and used for fluid typing and pore size [16]-[22]. It can also help in finding the contribution of Bitumen, Kerogen, Bound water, moveable water and hydrocarbon by 2D T1-T2 map or using ratios of $\mathrm{T} 1 / \mathrm{T} 2$.

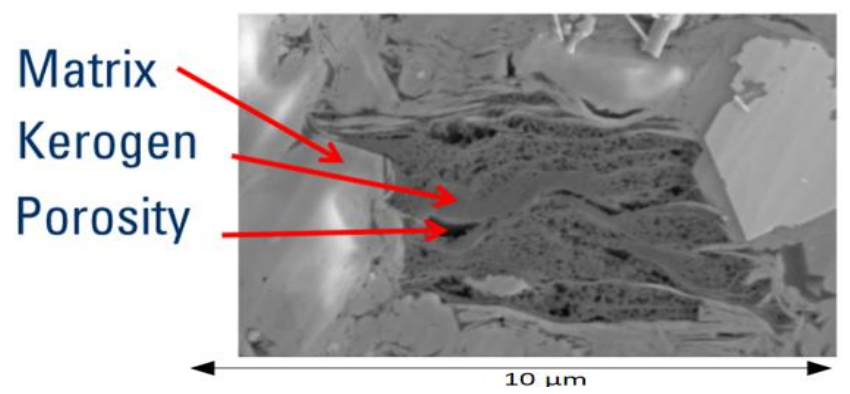

Fig. 2. Pore system in a shale rock sample from [2].

High Frequency NMR measures all hydrogen present in water, oil and solid organics. T1 and T2 relaxation times are physical properties of a sample and are related to mobility of molecules, so they can be used to differentiate liquids from solid, and also talk about mobilty. If $\mathrm{T} 1$ and $\mathrm{T} 2$ will be measured simultaneously, T1-T2 map will be resulted which provid hydrogen intensity map. The different Hydrogen contents in the T1-T2 map can be associated with the origins stated in Table II.

We used a modified CPMG (Carr-Purcell Meiboom-Gill) sequence in which inter-echo time increased gradually up to $100 \mu \mathrm{s}$ or more to catch very short and very long relaxation times [23]. 2D T1-T2 maps were then determined using an inversion recovery sequence. Fig. 3 shows T1-T2 map for two samples in this study from Bakken Formation. As it can be seen, the map is a very efficient way to separate the contributions from the different compartments containing hydrogen molecules.

TABLE II: ORIGIN OF DIFFERENT HYDROGEN CONTENT IN NMR

\begin{tabular}{lc}
\hline Hydrogen content & \multicolumn{1}{c}{ Origin } \\
\hline Hydroxyls & $\begin{array}{c}\text { OH part of the clay structure or at the edges of } \\
\text { clay platelets; it is always below } 0.1 \mathrm{~ms} \text {, and } \\
\text { needs appropriate NMR instruments }\end{array}$ \\
kerogen & $\begin{array}{c}\text { Based on the maturity, it can overlap with } \\
\text { hydroxyls. It is best detected in dry samples since } \\
\text { their hydrogen index is quite low compared to } \\
\text { water }\end{array}$ \\
\hline Water & It is located close to the line T1/T2 2 \\
\hline Methane & It can easily be separated on T1/T2 10 \\
\hline
\end{tabular}

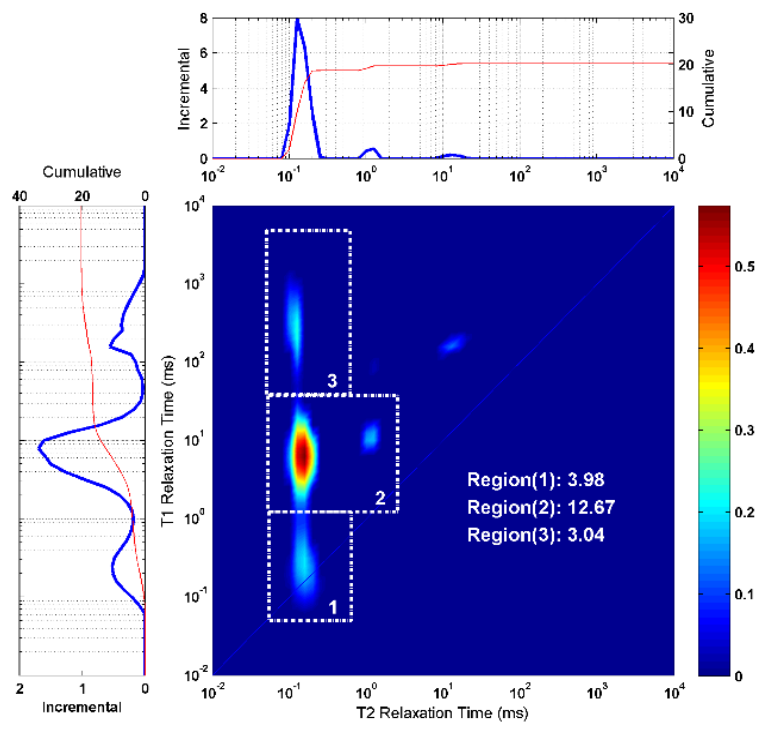

(a)
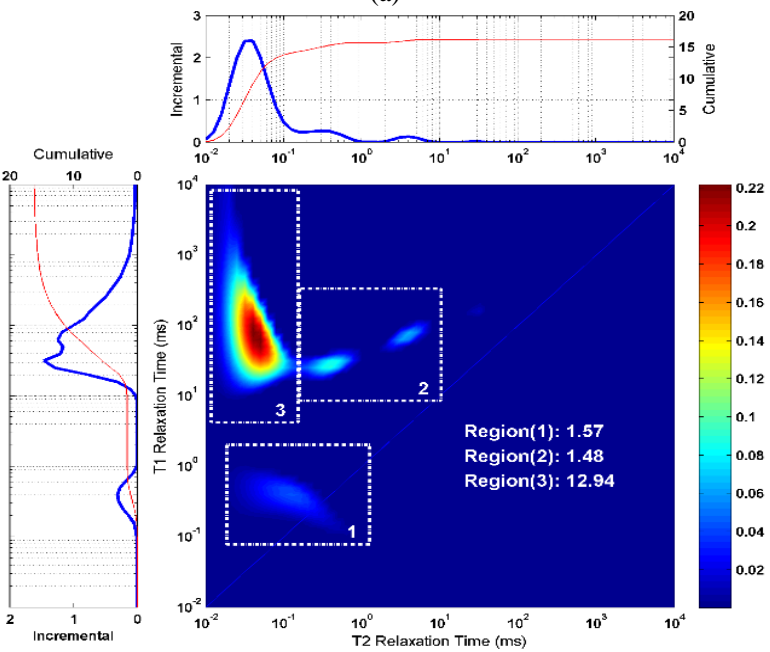

(b)

Fig. 3. T1-T2 map for: (a) Well No. 1 Upper Bakken, (b) Well No. 2 Lower Bakken. Hydrogen fraction for different regions are also shown.

\section{RESUlTS AND DISCUSSION}

Analyzing the core samples from which the organic matter 
was isolated showed hydroxyls from the clay are characterized with $0.01<\mathrm{T} 2<0.1 \mathrm{~ms}$ and $10<\mathrm{T} 1 / \mathrm{T} 2<100 \mathrm{and} /$ or spread over a wide $\mathrm{T} 1$ range, as region 3 in Well No. 2. Kerogen showed itself with $10<\mathrm{T} 1 / \mathrm{T} 2<100$, as in Region 2 and 3 in Well No. 1. It should be noted, in the gas window, organic matter cannot be distinguished, due to low maturity which leads to overlapping of Kerogen signal with the hydroxyl signal. Methane showed itself with T1/T2 10, as in Region 4 and 2 in Well No. 1 and Well No. 2, respectively. By changing pore size, it moves towards higher T1 and T2 values, as in Region 2 in Well No. 2. Water showed itself with T1/T2 2, as in Region 1 in both Well No. 1 and Well No. 2. Moreover, the $\mathrm{T} 1$ axis can roughly represents the proton rotational mobility [3]-[24]. The mobility is small for large T1/T2 ratios, whereas for solid protons, it corresponds to reduced molecular mobility. Low viscosity fluids have $\mathrm{T} 1 / \mathrm{T} 2=1$ (like water), but high viscosity fluids have T1/T2 >100 (like Bitumen).

Reference [3] and [24] proposed typical T1-T2 map, which distinguishes between different hydrogen content based on their location in T1-T2 map, Fig. 4.

Interestingly, Photomicrographs of Well No. 2 under UV light (fluorescence) showed presence of HC, Fig. 5.

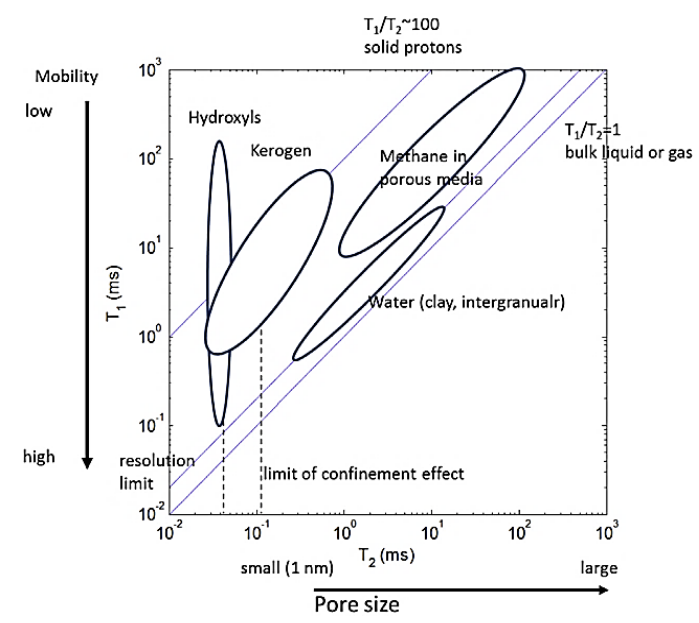

Fig. 4. T1-T2 map proposed by [3] to find each hydrogen content based on location.

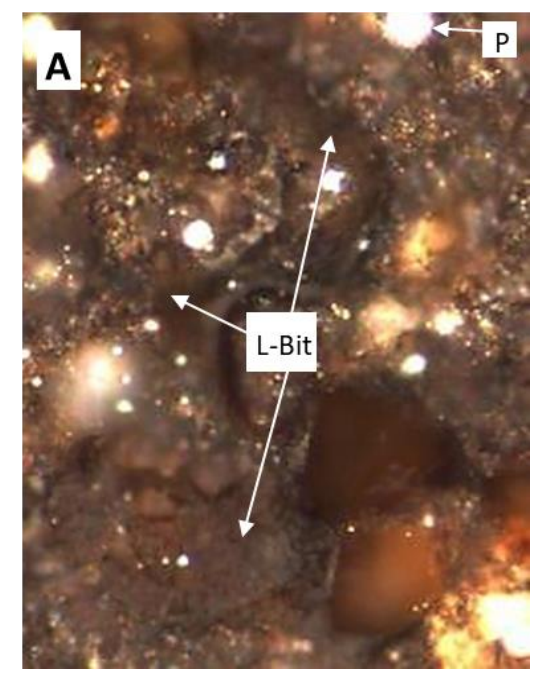

(a)

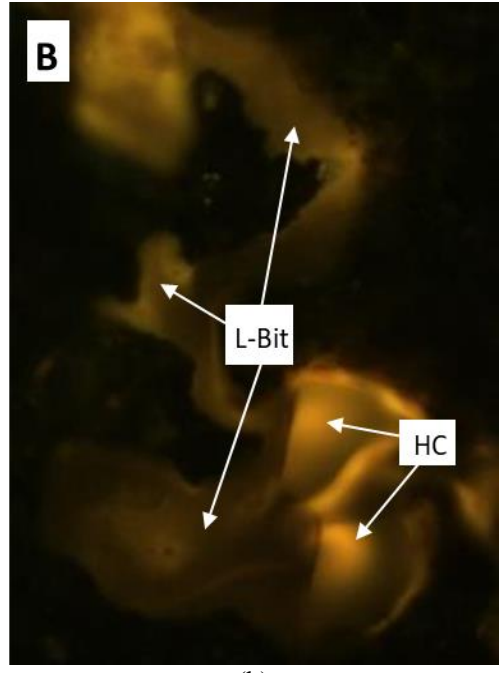

(b)

Fig. 5. (a) Low-reflecting bitumen (L-Bit) for Well No. 2 (b) the same view as in (a) but under UV light. Note the dull-yellow fluorescence color of the generated hydrocarbon (HC) filling the cavities. P is also showing Pyrite.

\section{CONCLUSION}

In this study, we had two samples from upper and lower Bakken formations. We used NMR T1-T2 map to distinguish between different Hydrogen contents in unconventional shale reservoirs as hydroxyls from the clay structure, kerogen, water and methane, since signals are not overlaping.

Estimation of the fluid properties in shales is challenging, and even using advance methods such as NMR needs more experimental work to develop a reliable correlations. This issue would be better performed by understanding the shale system fully. NMR method, might be a benefical tool to help us in this way.

\section{ACKNOWLEDGMENT}

Authors thanks Core Laboratories in Houston for their helps and valuable advices to improve the paper quality.

\section{REFERENCE}

[1] M. Josh, L. Esteban, C. Delle Piane, J. Sarout, D. N. Dewhurst, and M. B. Clennell, "Laboratory characterisation of shale properties," Journal of Petroleum Science and Engineering, vol. 88, pp. 107-124, 2012.

[2] R. G. Loucks, R. M. Reed, S. C. Ruppel, and U. Hammes, "Preliminary classification of matrix pores in mudrocks," Gulf Coast Association of Geological Societies Transactions, vol. 60, pp. 435-441, 2010.

[3] M. Fleury and M. Romero-Sarmiento, "Characterization of shales using T 1-T 2 NMR maps," Journal of Petroleum Science and Engineering, vol. 137, pp. 55-62, 2016.

[4] J. Piedrahita and R. Aguilera, "Estimating oil saturation index osi from nmr logging and comparison with rock-eval pyrolysis measurements in a shale oil reservoir," in Proc. SPE Unconventional Resources Conference, Calgary, Alberta, Canada, February 15-16, 2017.

[5] S. R. Kelemen, M. Afeworki, M. L. Gorbaty, M. Sansone, P. J. Kwiatek, C. C. Walters, H. Freund, et al., "Direct characterization of kerogen by $\mathrm{X}$-ray and solid-state $13 \mathrm{C}$ nuclear magnetic resonance methods," Energy \& Fuels, vol. 21, no. 3, pp. 1548-1561, 2007.

[6] U. Werner-Zwanziger, G. Lis, M. Mastalerz, and A. Schimmelmann, "Thermal maturity of type II kerogen from the new albany shale assessed by 13 C CP/MAS NMR," Solid State Nuclear Magnetic Resonance, vol. 27, no. 1, pp. 140-148, 2005.

[7] J. Mao, X. Fang, Y. Lan, A. Schimmelmann, M. Mastalerz, L. Xu, and K. Schmidt-Rohr, "Chemical and nanometer-scale structure of kerogen 
and its change during thermal maturation investigated by advanced solid-state 13 C NMR spectroscopy," Geochimica et Cosmochimica Acta, vol. 74, no. 7, pp. 2110-2127, 2010.

[8] K. E. Washburn and J. E. Birdwell, "Updated methodology for nuclear magnetic resonance characterization of shales," Journal of Magnetic Resonance, vol. 233, pp. 17-28, 2013.

[9] X. Cao, J. E. Birdwell, M. A. Chappell, Y. Li, J. J. Pignatello, and J. Mao, "Characterization of oil shale, isolated kerogen, and postpyrolysis residues using advanced 13C solid-state nuclear magnetic resonance spectroscopy," AAPG Bulletin, vol. 97, no. 3, pp. 421-436, 2013.

[10] Y. Feng, T. V. L. Doan, and A. E. Pomerantz, "The chemical composition of bitumen in pyrolyzed green river oil shale: Characterization by 13C NMR spectroscopy," Energy \& Fuels, vol. 27, no. 12 , pp. 7314-7323, 2013.

[11] M. S. Solum, C. L. Mayne, A. M. Orendt, R. J. Pugmire, J. Adams, and T. H. Fletcher, "Characterization of macromolecular structure elements from a green river oil shale, I. Extracts," Energy \& Fuels, vol. 28, no. 1, pp. 453-465, 2013.

[12] J. P. Korb, A. Louis-Joseph, and L. Benamsili, "Probing structure and dynamics of bulk and confined crude oils by multiscale NMR spectroscopy, diffusometry, and relaxometry," The Journal of Physical Chemistry B, vol. 117, no. 23, pp. 7002-7014, 2013.

[13] A. B. Andrews, J. C. Edwards, A. E. Pomerantz, O. C. Mullins, D. Nordlund, and K. Norinaga, "Comparison of coal-derived and petroleum asphaltenes by 13C nuclear magnetic resonance, DEPT, and XRS," Energy \& Fuels, vol. 25, no. 7, pp. 3068-3076, 2011.

[14] N. V. Lisitza, D. E. Freed, P. N. Sen, and Y. Q. Song, "Study of asphaltene nanoaggregation by nuclear magnetic resonance (NMR)," Energy \& Fuels, vol. 23, no. 3, pp. 1189-1193, 2009.

[15] R. Dutta Majumdar, M. Gerken, R. Mikula, and P. Hazendonk, "Validation of the Yen-Mullins model of Athabasca oil-sands asphaltenes using solution-state 1H NMR relaxation and 2D HSQC spectroscopy," Energy \& Fuels, vol. 27, no. 11, pp. 6528-6537, 2013.

[16] A., Tinni, E. Odusina, I. Sulucarnain, C. Sondergeld, and C. Rai, "NMR response of brine, oil and methane in organic rich shales," in Proc. SPE Unconventional Resources Conference, The Woodlands, Texas, USA, April 1-3, 2014.

[17] E. Odusina and R. F. Sigal, "Laboratory NMR measurements on methane saturated Barnett Shale samples," Petrophysics, vol. 52, no. 1, pp. 32-49, 2011.

[18] R. Lewis, P. Singer, T. Jiang, E. Rylander, S. Sinclair, and R. H. Mclin, "NMR T2 distributions in the Eagle Ford shale: Reflections on pore size," in Proc. SPE Unconventional Resources Conference, USA, The Woodlands, Texas, USA, April 10-12, 2013.

[19] A. Alexeyev, M. Ostadhassan, R. A. Mohammed, B. Bubach, S. Khatibi, C. Li, and L. Kong, "Well log based geomechanical and petrophysical analysis of the bakken formation," presented at 51st U.S. Rock Mechanics/Geomechanics Symposium, San Francisco, California, USA, June 25-28, 2017.

[20] M. G. Smith and R. M. Bustin, "Late devonian and early mississippian bakken and exshaw black shale source rocks, Western Canada sedimentary basin: A sequence stratigraphic interpretation," $A A P G$ Bulletin, vol. 84, no. 7, pp. 940-960, 2000

[21] M. G. Smith, R. M. Bustin, and M. L. Caplan, "Sequence stratigraphy of the Bakken and Exshaw formations: A continuum of black shale formations in the Western Canada Sedimentary Basin," presented at Seventh International Williston Basin Symposium, July 23, 1995.
[22] A. E. Ozen, "Comparisons of T1 and T2 NMR relaxations on shale cuttings," Ph.D. dissertation, Dept. Petroleum Eng., University of Oklahoma, Norman, Oklahoma, USA, 2011.

[23] R. Siegel, T. T. Nakashima, and R. E. Wasylishen, "Application of multiple-pulse experiments to characterize broad NMR chemical-shift powder patterns from spin-1/2 nuclei in the solid state," The Journal of Physical Chemistry B, vol. 108, no. 7, pp. 2218-2226, 2004.

[24] K. Viswanathan, R. Kausik, C. C. Minh, L. Zielinski, B. Vissapragada, R. Akkurt, Y. Q. Song, C. Liu, S. Jones, and E. Blair, "Characterization of gas dynamics in kerogen nanopores by NMR," in Proc. SPE Annual Technical Conference and Exhibition, Denver, Colorado, USA, Oct. 30Nov. 2, 2011.

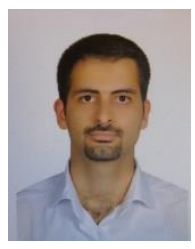

Seyedalireza Khatibi was born in Iran in 1989. He got his bachelor and master degree in the field of petroleum engineering at Amirkabir University (Tehran Polytechnique) in 2011 and 2013, respectively. Seyedalireza is now a PhD student at University of North Dakota, USA.

He started working as a geoscientist (geophysics section) in an oil company working on south pars gas field for less than four years and though away from school his enthusiasm was not dampened and published some paper on Geomachanics.

Mr. Khatibi is a student member of SPE (Society of Petroleum Engineers), AGU (American Geophysical Union), and also vice president of SEG (Society of Exploration Geophysicists) student chapter of UND.

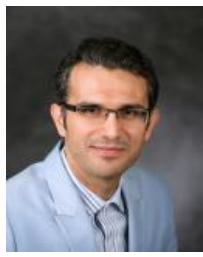

Mehdi Ostadhassan is an assistant professor in the Department of Petroleum Engineering at the University of North Dakota. Mehdi joined the petroleum department in Aug., 2013. Before starting his appointment at UND, he worked for several years in the industry as a petroleum geophysicist at various capacities. He also served as the energy division manager for the Atlantic Int. Operation, a UAE based company over a year. Mehdi's research is an integration of petroleum geoscience and engineering and is mainly focused on the characterization of the unconventional reservoirs.

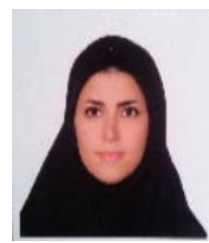

Azadeh Aghajanpour received her bachelor and master degrees from Amirkabir University of Technology in 2012 and 2014, respectively. She is currently a PhD student at Curtin University Malaysia and working on drilling and Geomechanics.

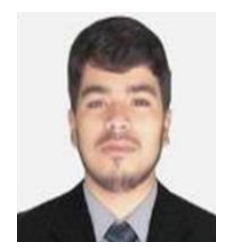

Rehan Ali mohammed currently works as drilling fluids and rock physics lab assistant at University of North Dakota. He is currently a graduate student in petroleum engineering at University of North Dakota, Grand Forks North Dakota, USA. He completed his bachelor's in petroleum (2015) engineering form Jawaharlal Nehru Technological University, Hyderabad, India. His Research interests are Rock Physics and Geomechanics. 